\title{
Tumor histology predicts mediastinal nodal status and may be used to guide limited lymphadenectomy in patients with clinical stage I non-small cell lung cancer
}

\author{
Xinghua Cheng, MD, PhD, ${ }^{a}$ Difan Zheng, MD, ${ }^{a}$ Yuan Li, MD, ${ }^{b}$ Hang Li, MD, ${ }^{a}$ Yihua Sun, MD, \\ Jiaqing Xiang, $\mathrm{MD},{ }^{\mathrm{a}}$ and Haiquan Chen, $\mathrm{MD}^{\mathrm{a}}$
}

\section{ABSTRACT}

Objective: Methods to minimize surgical trauma from mediastinal lymphadenectomy in patients with early-stage lung cancer are still immature. This study aimed to identify predictors of negative pathologic N2, which may be used to select patients for limited mediastinal lymphadenectomy.

Methods: Clinicopathologic features of 1430 patients with resected clinical stage I non-small cell lung cancer and complete mediastinal lymphadenectomy were retrospectively analyzed for variables associated with negative N2 nodal metastasis (2008-2015). Overall and recurrence-free survival in patients after complete or limited mediastinal lymphadenectomy were assessed via Kaplan-Meier survival analysis and log-rank testing. The accuracy of frozen section diagnosis for predicting final pathology was retrospectively assessed in 126 randomly selected patients after the surgery.

Results: Multivariable analysis revealed that tumor size $\leq 2 \mathrm{~cm}$, negative $\mathrm{pN} 1$, lymphovascular invasion, and lepidic adenocarcinoma were associated with negative mediastinal nodal metastasis. Notably, none of the patients with histology of adenocarcinoma in situ, minimally invasive adenocarcinoma, or lepidic pattern-predominant adenocarcinoma on final pathology had $\mathrm{pN} 2$ disease, and the 5-year overall and recurrence free-survival of these patients $(99.3 \%$ and $99.3 \%$, respectively) was not different from those after limited mediastinal lymphadenectomy ( $98.7 \%$ and $100 \%, P=.582$ and .511 , respectively). If these subtypes were classified together as the low-risk group, the concordance rate between frozen section and final pathology diagnosis was $88.9 \%$ in the retrospective test cohort.

Conclusions: Tumor histology may predict negative mediastinal metastasis in patients with early-stage lung cancer. Future prospective studies are merited to validate the feasibility of using frozen section to select patients for limited mediastinal lymphadenectomy. (J Thorac Cardiovasc Surg 2018;155:2648-56)

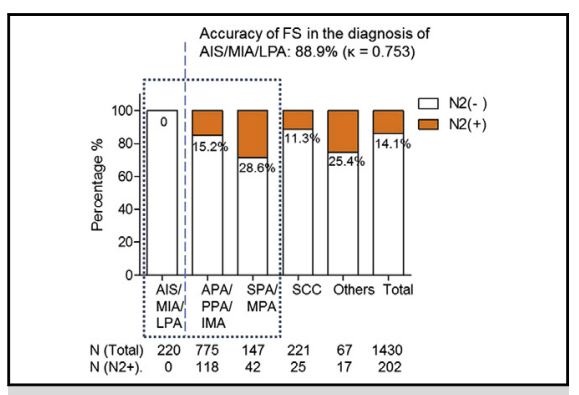

Selection of patients with low risk of pN2 by frozen section diagnosis in cStage I NSCLC.

\section{Central Message}

Lepidic-predominant histology predicts negative pN2 in clinical stage I non-small cell lung cancer.

\section{Perspective}

Lepidic histology in associated with negative pN2 in early-stage non-small cell lung cancer. Intraoperative identification of tumor with lepidic-predominant histology on frozen section may be applied in selecting patients for limited mediastinal lymphadenectomy in the future to minimize surgical trauma.

See Editorial Commentary page 2657.
From the Departments of ${ }^{\mathrm{a}}$ Thoracic Surgery and ${ }^{\mathrm{b}}$ Pathology, Fudan University Shanghai Cancer Center Shanghai, China

This work was supported by the National Natural Science Foundation of China $(81330056,81572253,81372525,81502480$, and 81572264) and a grant from the Health and Family Planning Commission of Shanghai Municipality (No. 2013ZYJB0301).

Drs Cheng and Zheng contributed equally to this article.

Received for publication Sept 6, 2017; revisions received Jan 26, 2018; accepted for publication Feb 5, 2018; available ahead of print March 13, 2018.

Address for reprints: Haiquan Chen, MD, Department of Thoracic Surgery, Fudan University Shanghai Cancer Center, 270 Dong An Rd, Shanghai, 200032, China (E-mail: hqchen1@yahoo.com).

0022-5223/\$36.00

Copyright (c) 2018 by The American Association for Thoracic Surgery

https://doi.org/10.1016/j.jtcvs.2018.02.010
Systematic mediastinal lymph node dissection is the golden standard of nodal staging in lung cancer surgery, which identifies patients who may benefit from adjuvant chemotherapy. ${ }^{1}$ However, in patients without nodal metastasis, prophylactic lymphadenectomy has no benefit on survival. ${ }^{2,3}$ Moreover, mediastinal lymphadenectomy

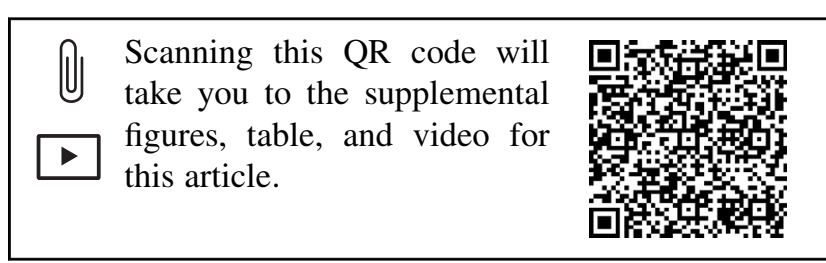




\author{
Abbreviations and Acronyms \\ AIS = adenocarcinoma in situ \\ APA = acinar pattern-predominant \\ adenocarcinoma \\ $\mathrm{CI}=$ confidence interval \\ $\mathrm{CT}=$ computed tomography \\ $\mathrm{FS} \quad=$ frozen section \\ GGO = ground-glass opacity \\ IMA = invasive mucinous adenocarcinoma \\ LPA = lepidic pattern-predominant \\ adenocarcinoma \\ MIA = minimally invasive adenocarcinoma \\ MPA = micropapillary pattern-predominant \\ adenocarcinoma \\ NSCLC $=$ non-small cell lung cancer \\ $\mathrm{OR}=$ odds ratio \\ OS = overall survival \\ PPA = papillary pattern-predominant \\ adenocarcinoma \\ RFS = recurrence-free survival \\ SPA $=$ solid pattern-predominant \\ adenocarcinoma
}

may increase operative time and drainage and may cause damage to neurogenic, vascular, and lymphatic structures within the mediastinum, leading to increased risk of postoperative morbidity such as chyle leaks and recurrent nerve injury. ${ }^{4-6}$

With advances in imaging techniques, a greater incidence of lung cancer is diagnosed at early stages, in which nodal metastasis is less common. ${ }^{7,8}$ The emerging challenge to thoracic surgeons now is how to minimize surgical trauma without compromising the effectiveness of the surgery in these patients. As significant improvements have been made in reducing incisional trauma and preserving lung parenchyma, achievement in minimizing damage from mediastinal lymph node dissection is still in its infancy. ${ }^{2,9}$ Although systematic mediastinal sampling may be as effective as dissection in term of survival, ${ }^{2}$ its value in reducing surgical trauma is insignificant. ${ }^{6}$ Other selective strategies for limited lymphadenectomy may reduce staging accuracy. ${ }^{9,10}$ The key to a good selective strategy is finding a reliable method that can correctly predict negative mediastinal nodal status. Currently, this method is lacking.

In this retrospective study, we aimed to investigate whether tumor histology can predict mediastinal nodal status in clinical stage I non-small cell lung cancer (NSCLC) and to test the accuracy of frozen section (FS) diagnosis for predicting histologic subtypes, which may be used as a tool to select patients for limited lymphadenectomy in the future.

\section{METHODS \\ Patients}

This retrospective study was approved by the institutional review board of Fudan University Shanghai Cancer Hospital. From April 2008 to February 2015, 2598 patients underwent resection for primary NSCLC and systematic mediastinal lymphadenectomy in our center. Preoperative tests including contrast-enhanced chest computed tomography (CT) scan, abdominal CT scan or ultrasonography, brain magnetic resonance imaging or CT scan, and radionuclide bone scan or position emission tomography/CT were performed. Clinical stage was determined according to the eighth edition of the tumor, node, and metastasis classification for lung cancer. ${ }^{11}$ After exclusion, 1430 patients with primary clinical stage I NSCLC were eligible for the retrospective evaluation (Figure 1). In addition, as the current study specifically excluded patients who did not have a complete lymphadenectomy, to evaluate the impact of limited mediastinal lymphadenectomy on survival of patients with lepidic pattern-predominant adenocarcinoma (LPA), 82 consecutive patients with a final pathologic diagnosis of LPA who had only limited mediastinal lymphadenectomy from the same time frame of the study, including 31 patients with no dissection and 51 patients with selective sampling, were also included for survival analysis.

\section{Definitions of Systematic and Limited Mediastinal Lymphadenectomy}

Systematic mediastinal lymph node dissection is defined as complete removal of at least 3 mediastinal nodal stations., ${ }^{2,12}$ In most cases, mediastinal stations $2 \mathrm{R}, 4 \mathrm{R}, 7$, and 8 for right-sided tumors and stations (Video 1) 5, 6, 7, and 8 for left-sided tumors were removed as the standard treatment. Station 9 was also removed for tumors located in the lower lobes. All hilar, lobar, and interlobar nodes were dissected as a part of lung resection. In some cases, limited mediastinal lymphadenectomy including no nodal dissection, incomplete mediastinal lymph node sampling, and dissections of no more than 2 mediastinal stations were performed if the tumor was subsolid on CT or had intraoperative FS diagnosis of adenocarcinoma in situ (AIS) or minimally invasive carcinoma (MIA). Lung resections including lobectomy, sublobar resection, and pneumonectomy were performed either via muscle-sparing thoracotomy or video-assisted approaches.

\section{Pathologic Evaluation}

After resection, all paraffin-embedded specimens were reviewed by at least 2 experienced pathologists and the final pathologic diagnosis was made based on the 2015 World Health Organization classification of lung tumors. ${ }^{13}$ Adenocarcinoma was further subtyped to AIS, MIA, LPA, acinar pattern-predominant adenocarcinoma (APA), papillary

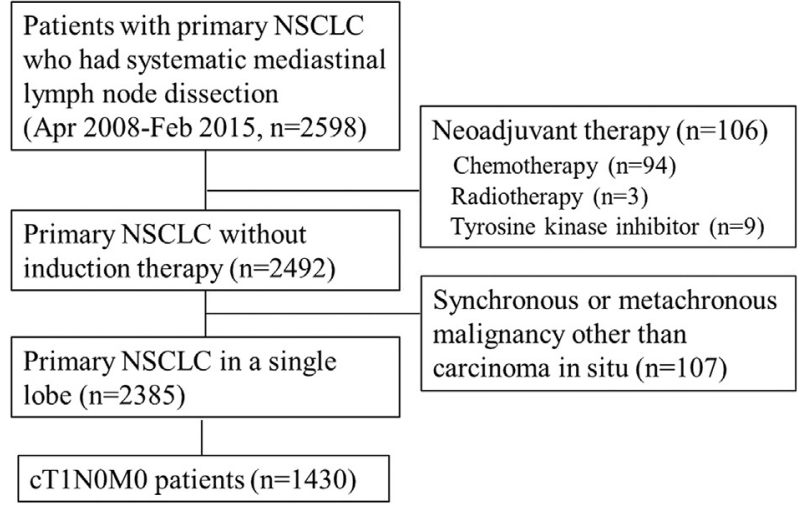

FIGURE 1. Consort diagram of patient selection. NSCLC, Non-small cell lung cancer. 


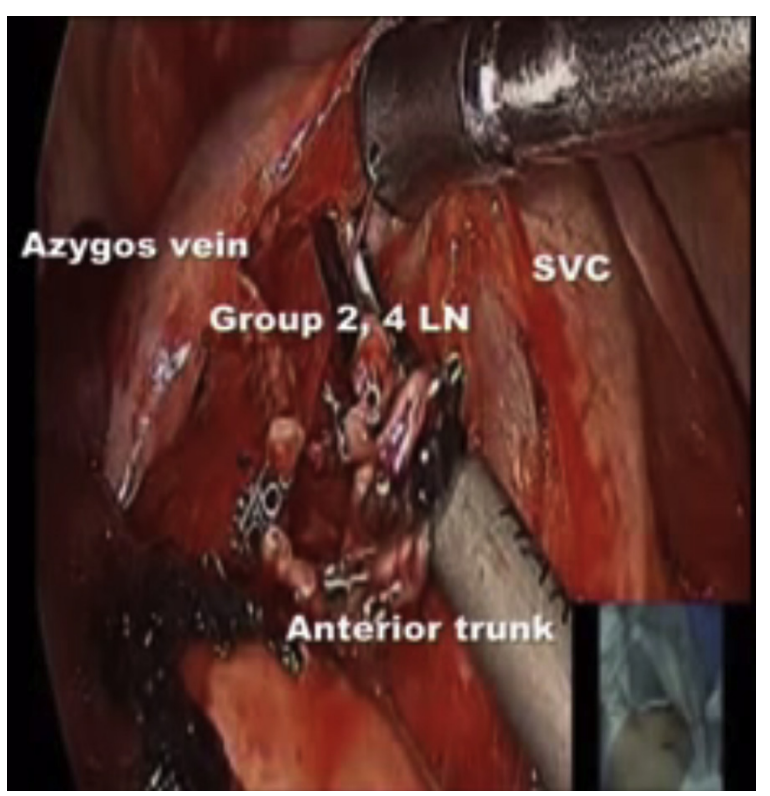

VIDEO 1. Complete mediastinal lymph node dissection via video-assisted thoracoscopic surgery or open thoracotomy.Video available at: http://www. jtcvsonline.org/article/S0022-5223(18)30362-3/fulltext.

pattern-predominant adenocarcinoma (PPA), micropapillary patternpredominant adenocarcinoma (MPA), solid pattern-predominant adenocarcinoma (SPA), and invasive mucinous adenocarcinoma (IMA) according to the histologic component with the greatest percentage. After January 2012, pathologists in our center made intraoperative FS diagnosis of AIS, MIA, invasive adenocarcinoma, squamous cell carcinoma, or other type of NSCLC to assist surgical decision. ${ }^{14}$ The tumor specimen was sliced at the largest diameter immediately after the resection and usually 1 to 2 sections of each specimen were made for FS diagnosis. To test the accuracy of FS in further subtyping adenocarcinoma, 126 cases of adenocarcinoma from the study cohort after January $2012(\mathrm{n}=754)$ were randomly selected in a ratio of 1 to 6 using a random number table. Their FS were retrospectively reviewed by 2 pathologists who were blinded to the final pathologic diagnosis, and the histologic subtypes were assigned to the tumors by the same criteria defined previously under a nonintraoperative setting.

\section{Patient Follow-up}

For the first 2 years, all patients were followed every 3 months and physical examination, chest CT scan, and abdominal ultrasonography were performed. The follow-up frequency was every 6 months for the third year and once per year for subsequent years. Brain magnetic resonance imaging or CT scan and bone scan were performed every year. Recurrence-free survival (RFS) was defined as the time from the date of the operation until the first recurrence or the last follow-up. Overall survival (OS) was defined as the interval between the date of the operation and the date of death or the last follow-up.

\section{Statistical Analysis}

The Pearson $\chi^{2}$ test was used to compare frequencies for categorical variables. Univariable regression was conducted, and the variables that were significant $(P<.05)$ were retained for multivariable logistic regression. To overcome the problem of "separation," a penalized maximum likelihood logistic regression in conventional logistic regression was used. ${ }^{15}$ Normality of the continuous variables were examined by Kolmogorov-Smirnov test, and the differences between groups were
TABLE 1. Characteristics of clinical stage I patients $(n=1430)$ with or without mediastinal lymph node metastasis

\begin{tabular}{|c|c|c|c|}
\hline & $\begin{array}{c}\text { Negative pN2 } \\
(n=1228) \\
n(\%)\end{array}$ & $\begin{array}{l}\text { Positive pN2 } \\
(n=202) \\
n(\%)\end{array}$ & $\boldsymbol{P}$ \\
\hline No. of nodes (median, IQR) & $16(11-22)$ & $19(14-24)$ & .001 \\
\hline Male & $634(86.0)$ & $103(14.0)$ & .866 \\
\hline Age, y $(\leq 60)$ & $585(86.2)$ & $94(13.8)$ & .771 \\
\hline Age (median, IQR) & $61(55-67)$ & $61(56-66)$ & .524 \\
\hline Smoking history & $381(85.0)$ & $67(15.0)$ & .543 \\
\hline Past malignancy & $120(86.3)$ & 19 (13.7) & .871 \\
\hline BMI $(\geq 24)$ & $424(82.3)$ & $91(17.7)$ & .004 \\
\hline $\begin{array}{c}\text { Location } \\
\text { RUL } \\
\text { LUL } \\
\text { RML } \\
\text { RLL } \\
\text { LLL }\end{array}$ & $\begin{array}{r}407(86.8) \\
372(87.9) \\
73(77.7) \\
204(84.3) \\
172(85.1)\end{array}$ & $\begin{array}{l}62(13.2) \\
51(12.1) \\
21(22.3) \\
38(15.7) \\
30(14.9)\end{array}$ & .106 \\
\hline $\begin{array}{l}\text { Pathology } \\
\text { AIS } \\
\text { MIA } \\
\text { LPA } \\
\text { APA } \\
\text { PPA } \\
\text { MPA } \\
\text { SPA } \\
\text { IMA } \\
\text { SCC } \\
\text { Others }\end{array}$ & $\begin{array}{c}19(100) \\
62(100) \\
139(100) \\
509(86.4) \\
114(79.2) \\
9(60) \\
96(72.7) \\
34(81.0) \\
196(88.7) \\
50(74.6)\end{array}$ & $\begin{array}{c}0 \\
0 \\
0 \\
80(13.6) \\
30(20.8) \\
6(40) \\
36(27.3) \\
8(19.0) \\
25(11.3) \\
17(25.4)\end{array}$ & $<.001$ \\
\hline $\begin{array}{l}\text { cStage } \\
\text { cIA1 } \\
\text { cIA2 } \\
\text { cIA3 } \\
\text { cIB }\end{array}$ & $\begin{array}{l}105(94.6) \\
483(91.0) \\
416(82.1) \\
224(79.7)\end{array}$ & $\begin{array}{c}6(5.4) \\
48(9.0) \\
91(17.9) \\
57(20.3)\end{array}$ & $<.001$ \\
\hline cSize, $\mathrm{cm}$, mean $\pm \mathrm{SD}$ & $2.3 \pm 0.9$ & $2.7 \pm 0.8$ & $<.001$ \\
\hline Positive N1 & $106(44.7)$ & $131(55.3)$ & $<.001$ \\
\hline Differentiation (poor) & $345(76.5)$ & $106(23.5)$ & $<.001$ \\
\hline VPI & $229(79.2)$ & $60(20.8)$ & $<.001$ \\
\hline LVI & $64(48.9)$ & $67(51.1)$ & $<.001$ \\
\hline NI & $22(73.3)$ & $8(26.7)$ & .046 \\
\hline Positive margin & $9(75)$ & $3(25)$ & .277 \\
\hline
\end{tabular}

$I Q R$, Interquartile range; $B M I$, body mass index; $R U L$, right upper lobe; $L U L$, left upper lobe; $R M L$, right middle lobe; $R L L$, right lower lobe; $L L L$, left lower lobe; $A I S$, adenocarcinoma in situ; $M I A$, minimally invasive adenocarcinoma; $L P A$, lepidic pattern-predominant adenocarcinoma; APA, acinar patternpredominant adenocarcinoma; $P P A$, papillary pattern-predominant adenocarcinoma; $M P A$, micropapillary pattern-predominant adenocarcinoma; SPA, solid patternpredominant adenocarcinoma; IMA, invasive mucinous adenocarcinoma; $S C C$, squamous cell carcinoma; $S D$, standard deviation; VPI, visceral pleural invasion; $L V I$, lymphovascular invasion; $N I$, neural invasion.

compared by the Student $t$ test for normally distributed data and by Mann-Whitney $U$ test or Kruskal-Wallis one-way analysis of variance for data that were not normally distributed. The concordance between FS and the final pathology diagnoses was evaluated by Cohen's Kappa 
TABLE 2. Univariate and multivariable regression analysis of factors associated with negative pN2

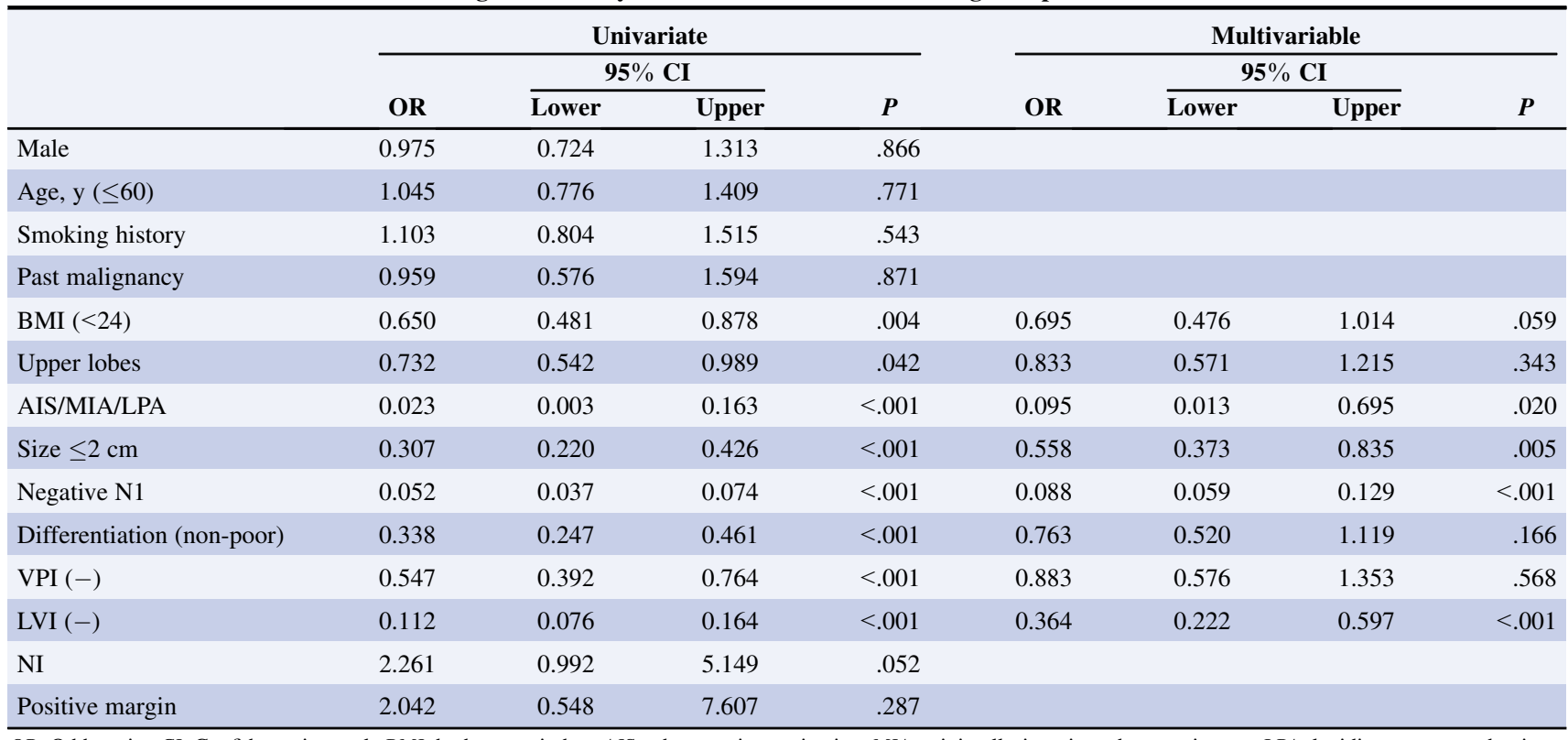

OR, Odds ratio; CI, Confidence interval; BMI, body mass index; $A I S$, adenocarcinoma in situ; $M I A$, minimally invasive adenocarcinoma; LPA, lepidic pattern-predominant adenocarcinoma; $V P I$, visceral pleural invasion; $L V I$, lymphovascular invasion; $N I$, neural invasion.

coefficient. The Kaplan-Meier method was used to analyze RFS and OS, and the log-rank test was used to compare differences between the groups. Statistical significance was set as $P<.05$. The statistical analyses were conducted via SPSS version 19.0 software (SPSS, Chicago, Ill) and Stata (Version SE/11.1; StataCorp, College Station, Tex).

\section{RESULTS}

\section{Patient Characteristics}

Clinicopathologic characteristics of patients with or without mediastinal lymph node metastasis are shown in Table 1 . The total upstaging rate was $21.6 \%$, including 106 patients $(7.4 \%)$ with only N1 metastasis, 71 patients $(5.0 \%)$ with only $\mathrm{N} 2$ metastasis, and 131 patients $(9.2 \%)$ with both $\mathrm{N} 1$ and $\mathrm{N} 2$ metastasis. A median of 16 lymph nodes were dissected, and more nodes were removed in the patients with $\mathrm{N} 2$ metastasis (19 vs 16 nodes in patients without N2 metastasis, $P<.001$ ). There was no difference in age, sex, smoking history, history of malignancy, tumor location, or marginal status between the 2 groups. The average tumor size was $2.3 \mathrm{~cm}$ in the N2-negative group and $2.7 \mathrm{~cm}$ in the N2-positive group $(P<.001)$. Moreover, pathological subtypes were significantly different between the 2 groups $(P<.001)$.

\section{Predictors of Negative Mediastinal Metastasis in Clinical Stage I NSCLC}

As presented in Table 2, risk factors associated with negative $\mathrm{pN} 2$ were identified by logistic regression analysis. Tumor with AIS/MIA/LPA histology (odds ratio [OR], $0.095 ; 95 \%$ confidence interval [CI], 0.013-0.695; $P=.020)$, tumor size $\leq 2 \mathrm{~cm}(\mathrm{OR}, 0.558$;
$95 \%$ CI, $0.373-0.835 ; P=.005)$, negative N1 metastasis (OR, 0.088; 95\% CI, 0.059-0.129; $P<.001$ ), and negative lymphovascular invasion (OR, $0.364 ; 95 \% \mathrm{CI}$, $0.222-0.597, P<.001)$ were factors associated with significantly reduced risk of $\mathrm{pN} 2$ as identified by both univariable and multivariable analysis.

\section{Mediastinal Nodal Metastasis in Different Histologic Subtypes of Clinical Stage I NSCLC}

The rates of pN2 in different histologic subtypes of clinical stage I NSCLC are shown in Figure 2. Overall, there were 1143 adenocarcinoma, 221 squamous cell carcinomas, and 67 other histologic types, including 32 adenosquamous carcinoma, 7 carcinoid, 20 large cell neuroendocrine carcinoma or large cell carcinoma with neuroendocrine morphology, 4 sarcomatoid carcinoma, and 5 not otherwise specified NSCLC. Adenocarcinomas were subdivided to 3 groups by their malignant grades $^{16}$ : the AIS/MIA/LPA group (low malignant grade), the APA/PPA/IMA group (median malignant grade), and the MPA/SPA group (high malignant grade). For the entire cohort, the $\mathrm{pN} 2$ rate increased from $5.4 \%$ in tumors $\leq 1 \mathrm{~cm}$ to $20.3 \%$ in tumors between 3.1 and $4 \mathrm{~cm}$. Nevertheless, none of patients with AIS $(n=20)$, MIA $(n=61)$, or LPA $(n=139)$ had mediastinal lymph node metastasis, indicating they may be eligible candidates of limited mediastinal lymphadenectomy. This group of patients also had no N1 metastasis or lymphovascular invasion and a significantly greater proportion of tumor $\leq 2 \mathrm{~cm}$ than other types of NSCLC $(P<.001 ;$ Figure E1) 

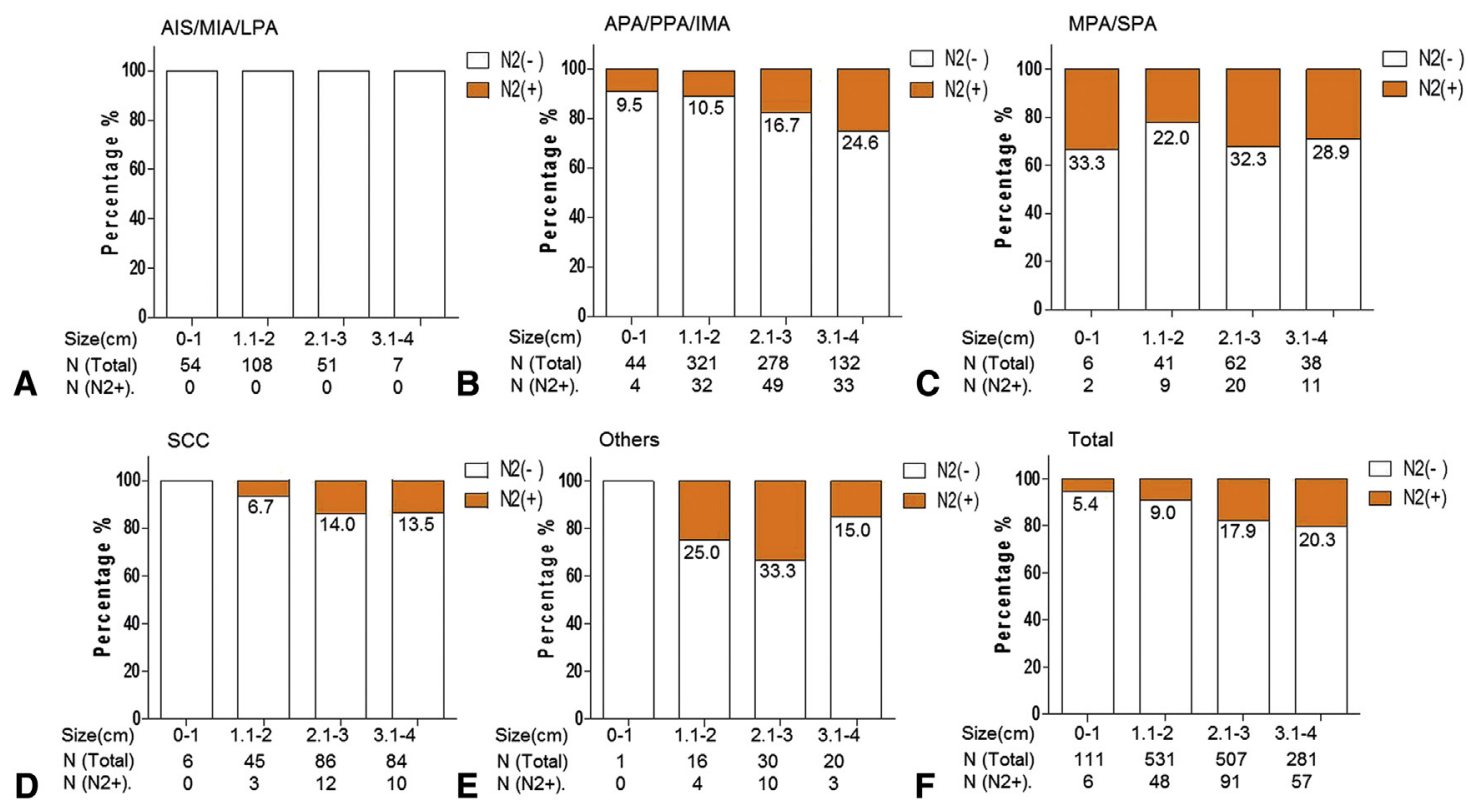

FIGURE 2. Mediastinal lymph node metastasis in different histologic subtypes of clinical stage I NSCLC. The percentages of pN2 are presented at different tumor sizes for patients with (A) AIS/MIA/LPA, (B) APA/PPA/IMA, (C) MPA/SPA, (D) SCC, and (E) other NSCLC. F, Overall pN2 rate in clinical stage I NSCLC. AIS, Adenocarcinoma in situ; MIA, minimally invasive adenocarcinoma; LPA, lepidic pattern-predominant adenocarcinoma; $A P A$, acinar pattern-predominant adenocarcinoma $P P A$, papillary pattern-predominant adenocarcinoma; IMA, invasive mucinous adenocarcinoma; $M P A$, micropapillary pattern-predominant adenocarcinoma; SPA, solid pattern-predominant adenocarcinoma; SCC, squamous cell carcinoma.

\section{Survival Analysis of Patients With Lepidic Adenocarcinoma}

Previously we showed the 5-year RFS and OS in patients with AIS/MIA who had sublobar resection without mediastinal lymphadenectomy were both $100 \%{ }^{14}$ In this study, the RFS and OS of an additional cohort of 82 patients with LPA who had only limited mediastinal lymphadenectomy were retrospectively reviewed (the median follow-up duration was 40 months, range 5.2-99.8 months). As shown in Figure 3, the survival of these patients (5-year OS and RFS: $98.7 \%$ and $100 \%$, respectively) was not different from the patients with LPA who had complete mediastinal lymph node dissection in the main study cohort (the median follow-up duration was 36.9 months; range 5.3-99.7 months;
5 year OS and RFS: $99.3 \%$ and $99.3 \% ; P=.582$ and .511 , respectively). Only 2 deaths occurred, and neither was cancer related. The survival of the patients with LPA was significantly better than the survival of other pN0 clinical stage I patients $(P<.001$, Figure E2). Postoperative complications in patients with LPA after systematic and limited mediastinal lymphadenectomy are shown in Table E1.

\section{Concordance Between FS and Final Pathology Diagnosis in Histologic Subtyping of Adenocarcinoma}

Previously, we have shown intraoperative FS as an effective method to identify patients with AIS/MIA for sublobar resection, but invasive adenocarcinoma was not
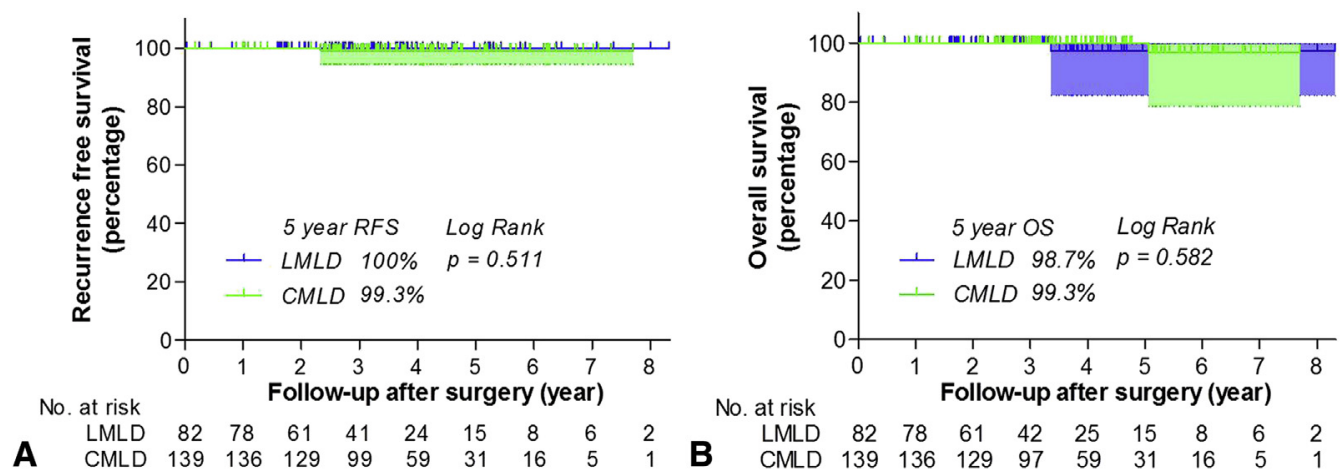

FIGURE 3. Survival of patients with LPA. The 5-year (A) RFS and (B) OS were not different between patients with LPA after LMLD (n $=82$ ) and those after CMLD ( $\mathrm{n}=139)$. RFS, Recurrence-free survival; $L M L D$, limited mediastinal lymphadenectomy; $C M L D$, complete mediastinal lymph node dissection; OS, overall survival. 
TABLE 3. Comparison of FS and final pathology diagnosis of subtypes of adenocarcinoma

\begin{tabular}{|c|c|c|c|c|c|c|}
\hline \multirow[b]{2}{*}{ FS diagnosis } & \multicolumn{4}{|c|}{ Final pathology diagnosis } & \multirow[b]{2}{*}{ Total } & \multirow[b]{2}{*}{ Kappa } \\
\hline & AIS/MIA & LPA & APA/PPA/IMA & $\overline{\text { MPA/SPA }}$ & & \\
\hline AIS/MIA & $19(0)$ & $2(0)$ & $1(0)$ & $0(0)$ & $22(0)$ & \\
\hline LPA & $0(0)$ & $15(0)$ & $6(0)$ & $0(0)$ & $21(0)$ & \\
\hline APA/PPA/IMA & $0(0)$ & $7(0)$ & $63(13)$ & $7(4)$ & $77(17)$ & \\
\hline MPA/SPA & $0(0)$ & $0(0)$ & $3(1)$ & $3(0)$ & $6(1)$ & \\
\hline Total & $19(0)$ & $24(0)$ & $73(14)$ & $10(4)$ & $126(18)$ & 0.647 \\
\hline
\end{tabular}

The number of patients with pN2 in each category is shown in parentheses. FS, Frozen section; $A I S$, adenocarcinoma in situ; $M I A$, minimally invasive adenocarcinoma; $L P A$, lepidic pattern-predominant adenocarcinoma; $A P A$, acinar pattern-predominant adenocarcinoma; $P P A$, papillary pattern-predominant adenocarcinoma; $I M A$, invasive mucinous adenocarcinoma; $M P A$, micropapillary pattern-predominant adenocarcinoma; SPA, solid pattern-predominant adenocarcinoma.

further subtyped by FS. ${ }^{14}$ In this study, FS of 126 adenocarcinomas were retrospectively reviewed and the histologic subtypes were diagnosed under a nonintraoperative setting. Subtypes of invasive adenocarcinoma were grouped into LPA, APA/PPA/IMA, and MPA/SPA according to their malignant grades (Table 3). ${ }^{16}$ Discrepancy in diagnosis between the FS and the final pathology were seen in 26 cases and the total concordance rate was $79.4 \%(\kappa=0.647)$. If the patients were further categorized to groups of AIS/MIA/LPA and other adenocarcinomas (Table 4), the concordance rate reached $88.9 \%(\kappa=0.753)$. Of the 14 nonconcordant cases by this categorization, 7 cases were underestimation of other invasive adenocarcinoma to AIS/MIA/LPA by FS, including 6 cases of APA and 1 case of PPA. All of them had lepidic pattern as their second predominant histologic subtype. None of the patients with FS diagnosis of AIS/MIA/LPA had N2 or N1 metastasis in the test cohort.

\section{DISCUSSION}

In this study, we retrospectively reviewed clinicopathologic results of 1430 clinical stage I NSCSC and identified tumor histology of AIS/MIA/LPA as a reliable predictor of negative N2 status. The OS and RFS of patients with lepidic adenocarcinoma who had limited mediastinal lymphadenectomy were not different from those who had complete mediastinal lymphadenectomy. In addition, the accuracy $(89.9 \%)$ of using FS diagnosis to identify this group of patients from other adenocarcinomas under a nonintraoperative setting was satisfactory $(\kappa=0.753)$, and none of the patients with FS diagnosis of AIS/MIA/ LPA had N2 metastasis. Therefore, avoidance of complete nodal dissection in these patients as guided by FS diagnosis may be a novel strategy to reduce surgical trauma in early-stage lung cancer, which merits further validation by prospective studies.

One of the main findings of this study is the identification of adenocarcinoma with predominant lepidic histology as a unique group in which systematic mediastinal lymph node dissection may be avoided. Regarding the survival, LPA either with or without complete lymphadenectomy had a 5 -year survival rate close to $100 \%$, suggesting limited lymphadenectomy is feasible in these patients. Lepidic adenocarcinoma is characterized by noninvasive tumor growth along intact alveolar wall, ${ }^{13}$ and based on the extent of invasion this type of tumor can be further categorized to AIS (pure lepidic growth), MIA (predominant lepidic growth with invasion $<5 \mathrm{~mm}$ ), and LPA (predominant lepidic growth with invasion $\geq 5 \mathrm{~mm}$ ). This group of adenocarcinomas typically presents with ground-glass opacity (GGO) feature on high-resolution $\mathrm{CT}^{17,18}$ and behaves less aggressively than other subtype of adenocarcinoma. ${ }^{16,17}$ The postoperative RFS and OS of lepidic adenocarcinoma are close to $100 \%,{ }^{18,19}$ and their incidence have been increasing recently possibly due to the spread of CT screening. ${ }^{7,8,17}$

Consistent with our results, Mimae and colleagues ${ }^{20}$ showed a significantly lower lepidic component ratio $(10 \%$ vs $50 \%)$ in patients with nodal metastasis. Yu and colleagues $^{21}$ also reported negative nodal involvement in 133 patients with LPA. Although description of tumor appearance on CT in this study is not available, previously Flores and colleagues ${ }^{8}$ and Hattori and colleagues ${ }^{18}$ showed the nodal metastasis rates in lung cancer with predominant

TABLE 4. Accuracy of FS in selecting patients with AIS/MIA/LPA

\begin{tabular}{|c|c|c|c|c|}
\hline \multirow[b]{2}{*}{ FS diagnosis } & \multicolumn{2}{|c|}{ Final pathology diagnosis } & \multirow[b]{2}{*}{ Total } & \multirow[b]{2}{*}{ Kappa } \\
\hline & $\overline{\text { AIS/MIA/LPA }}$ & Other AD & & \\
\hline AIS/MIA/LPA & $36(0)$ & $7(0)$ & $43(0)$ & \\
\hline Other AD & $7(0)$ & $76(18)$ & $83(-18)$ & \\
\hline Total & $43(0)$ & $83(0)$ & $126(18)$ & 0.753 \\
\hline
\end{tabular}

The number of patients with $\mathrm{pN} 2$ in each category is shown in parentheses. FS, Frozen section; $A I S$, adenocarcinoma in situ; MIA, minimally invasive adenocarcinoma; LPA, lepidic pattern-predominant adenocarcinoma; $A D$, adenocarcinoma. 
GGO appearance were close to zero. However, as precise measurement of GGO lesion on CT is still challenging, its use in assisting clinical decision remains datable. ${ }^{17,22}$

Other noninvasive or less-invasive methods to assess nodal status have been described previously. ${ }^{2,6,8,10,23}$ Direct nodal staging by CT or position emission tomography/CT may understage $10 \%$ to $30 \%$ of patients. ${ }^{24,25}$ Consistently, $21.6 \%$ of patients in this study were upstaged by systematic nodal dissection $(7.4 \%$ with $\mathrm{pN} 1$ and $14.2 \%$ with $\mathrm{pN} 2$ ). Random lymph node sampling is associated with $\sim 10 \%$ lower $\mathrm{pN} 2$ rate than dissection, ${ }^{10}$ and the number of sampled nodes correlates with survival in early-stage patients. ${ }^{26,27}$ In the randomized ACOSOG-Z0030 trial, although systematic mediastinal lymph node sampling was as effective as dissection in term of survival in the patient with $\mathrm{N} 0$ or $\mathrm{N} 1$ NSCLC, ${ }^{2}$ it still missed $4 \%$ of $\mathrm{pN} 2$ cases and did not reduce surgical morbidity. ${ }^{2,6}$ Tumor size $<1 \mathrm{~cm}$ used to be suggested as an indicator of pN0 status. ${ }^{28,29}$ However, in both our study and studies by others $\mathrm{pN} 2$ were seen in $2.1 \%$ to $5.4 \%$ of tumors $\leq 1 \mathrm{~cm} \cdot{ }^{30,31}$ Moreover, as shown in the results, the difference in average tumor size between N2-positive and N2-negative tumors was only $4 \mathrm{~mm}$. Pathologic tumor size is hardly available on FS and radiographic tumor size is usually inaccurate, especially in patients with lepidic tumors, all suggesting tumor size is not a reliable discriminating factor. ${ }^{32}$ Lobe-specific lymphadenectomy is another selective strategy for limited lymphadenectomy, ${ }^{33}$ in which regional mediastinal dissection is performed based on tumor location and FS assessment of N1 nodes. However, this strategy may also have reduced upstaging rate $(13.8 \%$ vs $21.1 \%)$ and lower $\mathrm{N} 2$ detection rate $(9.0 \%$ vs $13.1 \%)$ than systematic dissection, ${ }^{10}$ possibly due to skip N2 metastasis, as seen in this study $(5 \%)$. None of the aforementioned methods has the staging accuracy equivalent to systematic mediastinal dissection.

The future possibility of using FS to discriminate patients with lepidic adenocarcinoma for limited lymphadenectomy was also tested retrospectively. Previously, we reported intraoperative FS had a high accuracy $(96.1 \%)$ for the diagnosis of AIS/MIA, and it is an effective way to guide sublobar resection in these patients (decisional errors in only $0.7 \%$ of patients). ${ }^{14}$ Similar studies examining the strength of FS for histologic subtyping are scarce. Yeh and colleagues ${ }^{34}$ retrospectively reviewed 361 resected stage I lung adenocarcinomas $\leq 3 \mathrm{~cm}$ (including 19 AIS/MIA and 53 LPA). The accuracy, sensitivity, and specificity of FS for the diagnosis of LPA were $90 \%$, $75 \%$, and $93 \%$, respectively. The majority of the diagnostic errors were underestimation of LPA to AIS or MIA. ${ }^{34}$ In the current study, the accuracy of FS in differentiating AIS/MIA/LPA from other subtypes of adenocarcinoma was satisfactory $(88.9 \%, \kappa=0.753)$ and none of the misdiagnosed cases had mediastinal metastasis. All 7 cases with underestimation of other adenocarcinoma to lepidic-predominant adenocarcinoma by FS had lepidic pattern as their second predominant subtype, whereas none of the tumors with $\mathrm{pN} 2$ in the test cohort had lepidic pattern more than $20 \%$. It is unlikely these patients would have been misdiagnosed as AIS/MIA/LPA by FS. Nevertheless, the actual impact of this selective strategy on staging accuracy needs to be examined in future studies.

This single institutional study was retrospective and contains several limitations. First, the accuracy of histologic subtyping of adenocarcinoma on FS was tested outside of the pressures of the intraoperative setting. Although the pathologists were blinded to the final pathology, they might have different diagnoses if they were subject to the pressures and restrictions of clinical impact. Also, the 126 randomly selected cases may not represent the whole population, and the probability of $\mathrm{N} 2$ disease may also vary in populations under different screening and follow-up strategies. ${ }^{7,35}$ Second, both the final pathology and FS diagnoses were made by pathologists only from our center. Interobserver/institution discrepancy may exist because of variations in experiences of the pathologists. ${ }^{34}$

Moreover, the diagnostic criteria of LPA have been modified in the past few years, and we used the 2015 World Health Organization classification for diagnosis, which may explain the discrepancy between previous reports and the current study. ${ }^{13}$ For the use of this strategy at other sites, we recommend as least 2 experienced pathologists for intraoperative diagnosis based on the 2015 World Health Organization criteria. Third, the survivals of patients with or without complete mediastinal lymph node dissection were compared retrospectively and there might be selective bias due to the surgeon's preoperative judgment on each tumor. The median follow-up time of the patients was relatively short, especially for indolent tumors like AIS/MIA/LPA. It is possible that the impact of lymphadenectomy on survival may be revealed after a longer period of follow-up. Lastly, as surgical procedures and conditions of the patients varied between the complete dissection group and the limited lymphadenectomy group, the impact of limited lymphadenectomy on clinical outcomes such as operative time and morbidity may not represent the real differences between the groups (Table E1). To overcome the aforementioned problems, prospectively designed, multi-institutional randomized trials with the consideration of staging accuracy, morbidity, and long-term survival should be conducted to further validate the proposed strategy of limited lymphadenectomy. Such a trial has been planned and registered in the ClinicalTrials.gov (NCT03216551) by us.

In summary, tumor histology of AIS/MIA/LPA is associated with a very low risk of mediastinal nodal metastasis in patients with clinical stage I NSCLC. 
Intraoperative FS diagnosis may be a useful tool to select this group of patients for limited mediastinal lymphadenectomy and reduce surgical trauma. Future prospective studies are merited to validate its clinical benefits in early-stage lung cancer.

\section{Conflict of Interest Statement}

Authors have nothing to disclose with regard to commercial support.

We acknowledge Ms Qiong Lu, Ms Jie Xu, and Ms Youjia Deng's contributions in collecting patients' clinical data for this work.

\section{References}

1. Asamura H, Chansky K, Crowley J, Goldstraw P, Rusch VW, Vansteenkiste JF, et al. The International Association for the Study of Lung Cancer Lung Cancer Staging Project: Proposals for the Revision of the $\mathrm{N}$ descriptors in the forthcoming 8th edition of the TNM classification for lung cancer. J Thorac Oncol. 2015;10:1675-84.

2. Darling GE, Allen MS, Decker PA, Ballman K, Malthaner RA, Inculet RI, et al. Randomized trial of mediastinal lymph node sampling versus complete lymphadenectomy during pulmonary resection in the patient with $\mathrm{N} 0$ or N1 (less than hilar) non-small cell carcinoma: results of the American College of Surgery Oncology Group Z0030 Trial. J Thorac Cardiovasc Surg. 2011;141: 662-70.

3. Izbicki JR, Passlick B, Pantel K, Pichlmeier U, Hosch SB, Karg O, et al. Effectiveness of radical systematic mediastinal lymphadenectomy in patients with resectable non-small cell lung cancer: results of a prospective randomized trial. Ann Surg. 1998;227:138-44.

4. Izbicki JR, Thetter O, Habekost M, Karg O, Passlick B, Kubuschok B, et al. Radical systematic mediastinal lymphadenectomy in non-small cell lung cancer: a randomized controlled trial. Br J Surg. 1994;81:229-35.

5. Chida M, Minowa M, Karube Y, Eba S, Okada Y, Miyoshi S, et al. Worsened long-term outcomes and postoperative complications in octogenarians with lung cancer following mediastinal lymph-node dissection. Interact Cardiovasc Thorac Surg. 2009;8:89-92.

6. Allen MS, Darling GE, Pechet TT, Mitchell JD, Herndon JE, Landreneau RJ, et al. Morbidity and mortality of major pulmonary resections in patients with early-stage lung cancer: initial results of the randomized, prospective ACOSOG Z0030 trial. Ann Thorac Surg. 2006;81:1013-9; discussion 1019-20.

7. National Lung Screening Trial Research Team, Church TR, Black WC, Aberle DR, Berg CD, Clingan KL, et al. Results of initial low-dose computed tomographic screening for lung cancer. N Engl J Med. 2013;368: 1980-91.

8. Flores RM, Nicastri D, Bauer T, Aye R, Andaz S, Kohman L, et al. Computed tomography screening for lung cancer: mediastinal lymph node resection in stage IA nonsmall cell lung cancer manifesting as subsolid and solid nodules. Ann Surg. 2017;265:1025-33.

9. Watanabe S, Asamura H. Lymph node dissection for lung cancer: significance, strategy, and technique. J Thorac Oncol. 2009;4:652-7.

10. Adachi H, Sakamaki K, Nishii T, Yamamoto T, Nagashima T, Ishikawa Y, et al. Lobe-specific lymph node dissection as a standard procedure in surgery for non-small cell lung cancer: a propensity score matching study. J Thorac Oncol. 2017; 12:85-93.

11. Goldstraw P, Chansky K, Crowley J, Rami-Porta R, Asamura H, Eberhardt WE, et al. The IASLC lung cancer staging project: proposals for revision of the TNM stage groupings in the forthcoming (eighth) edition of the TNM classification for lung cancer. J Thorac Oncol. 2016;11:39-51.

12. Rusch VW, Asamura H, Watanabe H, Giroux DJ, Rami-Porta R, Goldstraw P, et al. The IASLC lung cancer staging project: a proposal for a new international lymph node map in the forthcoming seventh edition of the TNM classification for lung cancer. J Thorac Oncol. 2009;4:568-77.

13. Travis WD, Brambilla E, Nicholson AG, Yatabe Y, Austin JH, Beasley MB, et al. The 2015 World Health Organization classification of lung tumors: impact of genetic, clinical and radiologic advances since the 2004 classification. J Thorac Oncol. 2015;10:1243-60.
14. Liu S, Wang R, Zhang Y, Li Y, Cheng C, Pan Y, et al. Precise diagnosis of intraoperative frozen section is an effective method to guide resection strategy for peripheral small-sized lung adenocarcinoma. J Clin Oncol. 2016; 34:307-13.

15. Heinze G, Schemper M. A solution to the problem of separation in logistic regression. Stat Med. 2002;21:2409-19.

16. Hung JJ, Jeng WJ, Chou TY, Hsu WH, Wu KJ, Huang BS, et al. Prognostic value of the new International Association for the Study of Lung Cancer/American Thoracic Society/European Respiratory Society lung adenocarcinoma classification on death and recurrence in completely resected stage I lung adenocarcinoma. Ann Surg. 2013;258:1079-86.

17. Detterbeck FC, Marom EM, Arenberg DA, Franklin WA, Nicholson AG, Travis WD, et al. The IASLC lung cancer staging project: background data and proposals for the application of TNM staging rules to lung cancer presenting as multiple nodules with ground glass or lepidic features or a pneumonic type of involvement in the forthcoming eighth edition of the TNM classification. J Thorac Oncol. 2016;11:666-80.

18. Hattori A, Matsunaga T, Hayashi T, Takamochi K, Oh S, Suzuki K, et al Prognostic impact of the findings on thin-section computed tomography in patients with subcentimeter non-small cell lung cancer. J Thorac Oncol. 2017; 12:954-62.

19. Araki K, Kidokoro Y, Hosoya K, Wakahara M, Matsuoka Y, Takagi Y, et al. Excellent prognosis of lepidic-predominant lung adenocarcinoma: low incidence of lymphatic vessel invasion as a key factor. Anticancer Res. 2014; 34:3153-6.

20. Mimae T, Tsutani Y, Miyata Y, Yoshiya T, Ibuki Y, Kushitani K, et al. Role of lymphatic invasion in the prognosis of patients with clinical node-negative and pathologic node-positive lung adenocarcinoma. J Thorac Cardiovasc Surg. 2014;147:1820-6.

21. Yu Y, Jian H, Shen L, Zhu L, Lu S. Lymph node involvement influenced by lung adenocarcinoma subtypes in tumor size $</=3 \mathrm{~cm}$ disease: a study of 2268 cases. Eur J Surg Oncol. 2016;42:1714-9.

22. Travis WD, Asamura H, Bankier AA, Beasley MB, Detterbeck F, Flieder DB, et al. The IASLC lung cancer staging project: proposals for coding $\mathrm{T}$ categories for subsolid nodules and assessment of tumor size in part-solid tumors in the forthcoming eighth edition of the TNM classification of lung cancer. $J$ Thorac Oncol. 2016;11:1204-23.

23. Hishida T, Miyaoka E, Yokoi K, Tsuboi M, Asamura H, Kiura K, et al Lobe-specific nodal dissection for clinical stage I and II NSCLC: Japanese multi-institutional retrospective study using a propensity score analysis. J Thorac Oncol. 2016;11:1529-37.

24. Darling GE, Maziak DE, Inculet RI, Gulenchyn KY, Driedger AA, Ung YC, et al. Positron emission tomography-computed tomography compared with invasive mediastinal staging in non-small cell lung cancer: results of mediastinal staging in the early lung positron emission tomography trial. J Thorac Oncol. 2011;6: $1367-72$.

25. D’Cunha J, Herndon JE II, Herzan DL, Patterson GA, Kohman LJ, Harpole DH, et al. Poor correspondence between clinical and pathologic staging in stage 1 non-small cell lung cancer: results from CALGB 9761, a prospective trial. Lung Cancer. 2005;48:241-6.

26. Liang W, He J, Shen Y, Shen J, He Q, Zhang J, et al. Impact of examined lymph node count on precise staging and long-term survival of resected non-small-cel lung cancer: a population study of the US SEER database and a chinese multi-institutional registry. J Clin Oncol. 2017;35:1162-70.

27. Gajra A, Newman N, Gamble GP, Kohman LJ, Graziano SL. Effect of number of lymph nodes sampled on outcome in patients with stage I non-small-cell lung cancer. J Clin Oncol. 2003;21:1029-34.

28. Tsutani Y, Miyata Y, Nakayama H, Okumura S, Adachi S, Yoshimura M, et al. Prediction of pathologic node-negative clinical stage IA lung adenocarcinoma for optimal candidates undergoing sublobar resection. J Thorac Cardiovasc Surg. 2012;144:1365-71.

29. Watanabe S, Oda M, Go T, Tsunezuka Y, Ohta Y, Watanabe Y, et al. Should mediastinal nodal dissection be routinely undertaken in patients with peripheral small-sized ( $2 \mathrm{~cm}$ or less) lung cancer? Retrospective analysis of 225 patients. Eur J Cardiothorac Surg. 2001;20:1007-11.

30. Zhang Y, Sun Y, Shen L, Li Y, Xiang J, Zhang Y, et al. Predictive factors of lymph node status in small peripheral non-small cell lung cancers: tumor histology is more reliable. Ann Surg Oncol. 2013;20:1949-54.

31. Miller DL, Rowland CM, Deschamps C, Allen MS, Trastek VF, Pairolero PC Surgical treatment of non-small cell lung cancer $1 \mathrm{~cm}$ or less in diameter. Ann Thorac Surg. 2002;73:1545-50; discussion 1550-1. 
32. Isaka T, Yokose T, Ito H, Imamura N, Watanabe M, Imai K, et al. Comparison between CT tumor size and pathological tumor size in frozen section examinations of lung adenocarcinoma. Lung Cancer. 2014;85:40-6.

33. Asamura H, Nakayama H, Kondo H, Imamura N, Watanabe M, Imai K, et al. Lobe-specific extent of systematic lymph node dissection for non-small cell lung carcinomas according to a retrospective study of metastasis and prognosis. J Thorac Cardiovasc Surg. 1999;117:1102-11.

34. Yeh YC, Nitadori J, Kadota K, Yoshizawa A, Rekhtman N, Moreira AL, et al. Using frozen section to identify histological patterns in stage I lung adenocarcinoma of $</=3 \mathrm{~cm}$ : accuracy and interobserver agreement Histopathology. 2015;66:922-38.

35. Aberle DR, DeMello S, Berg CD, Black WC, Brewer B, Church TR, et al Results of the two incidence screenings in the National Lung Screening Trial. N Engl J Med. 2013;369:920-31.

Key Words: early-stage lung cancer, frozen section, limited mediastinal lymphadenectomy 


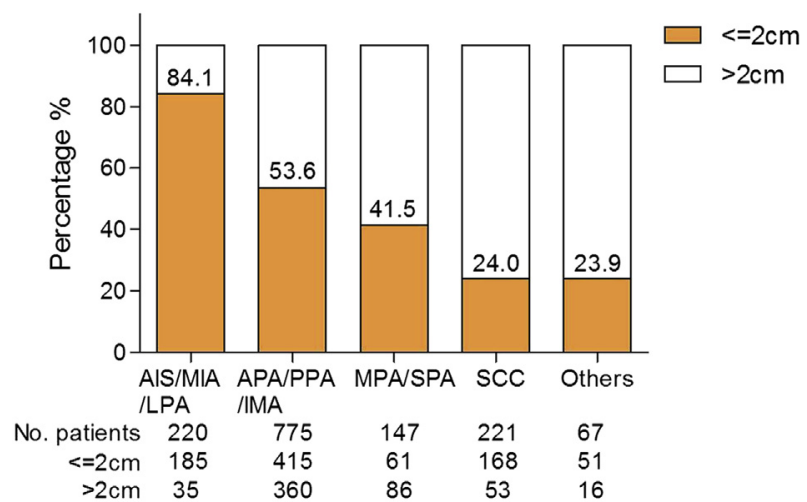

FIGURE E1. Proportions of tumors $\leq 2 \mathrm{~cm}$ in patients with different histologic subtypes of clinical stage I NSCLC. The percentages of tumor $\leq 2 \mathrm{~cm}$ are presented for patients with AIS/MIA/LPA, APA/PPA/IMA, MPA/SPA, SCC, and other NSCLC. AIS, Adenocarcinoma in situ; MIA, minimally invasive adenocarcinoma; $L P A$, lepidic pattern-predominant adenocarcinoma; APA, acinar pattern-predominant adenocarcinoma $P P A$, papillary patternpredominant adenocarcinoma; IMA, invasive mucinous adenocarcinoma; MPA, micropapillary pattern-predominant adenocarcinoma; SPA, solid pattern-predominant adenocarcinoma; $S C C$, squamous cell carcinoma.
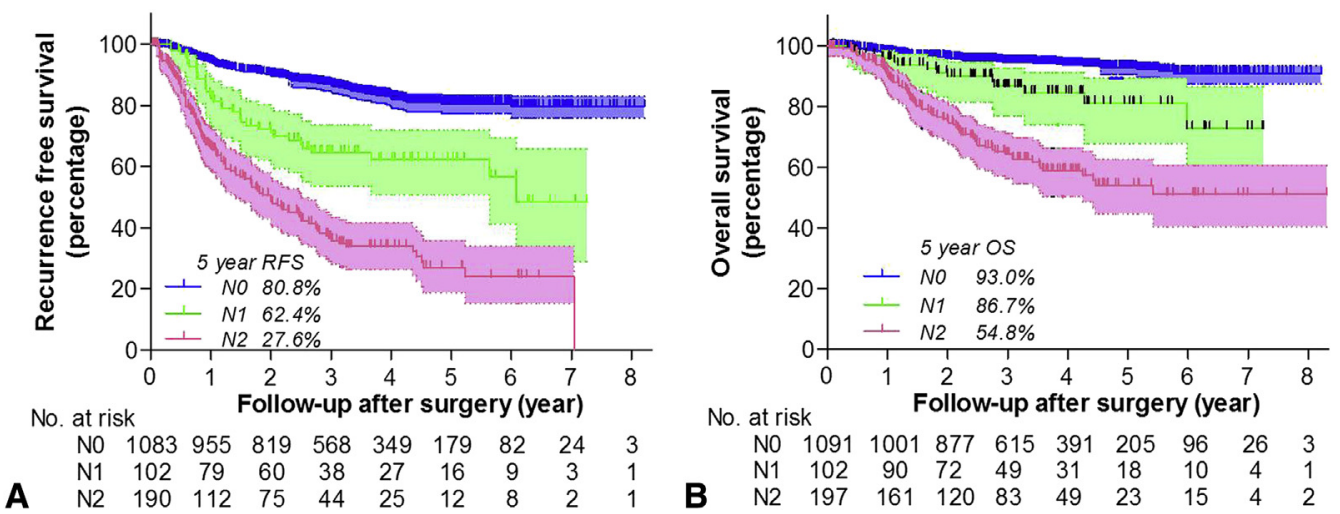

FIGURE E2. Survivals of patients with clinical stage I NSCLC. The (A) RFS and (B) OS were significantly different among patients with clinical stage I NSCLC who had pN0 $(\mathrm{n}=1122)$, pN1 $(\mathrm{n}=106)$, and pN2 $(\mathrm{n}=202)$ metastasis. The 5-year RFS and OS of patients with lepidic adenocarcinoma were significantly better than other pNO NSCLC $(99.3 \%$ vs $77.1 \%, P<.001$ and $99.3 \%$ vs $91.5 \%, P=.001$, respectively). $R F S$, Recurrence-free survival; $O S$, overall survival. 
TABLE E1. Surgical and postoperative parameters of patients with LPA by type of mediastinal lymphadenectomy

\begin{tabular}{|c|c|c|c|c|}
\hline & \multirow[b]{2}{*}{$\frac{\operatorname{CMLD}(\mathbf{n}=139)}{n(\%)}$} & \multicolumn{2}{|c|}{ LMLD } & \multirow[b]{2}{*}{$P$} \\
\hline & & $\frac{\overline{\text { Sampling }(\mathrm{n}=\mathbf{5 1})}}{\mathrm{n}(\%)}$ & $\frac{\text { No dissection }(n=31)}{n(\%)}$ & \\
\hline Surgical type & & & & $<.001$ \\
\hline Lobectomy & $122(87.8)$ & $36(70.6)$ & $6(19.4)$ & \\
\hline Segmentectomy & $14(10.1)$ & $6(11.8)$ & $5(16.1)$ & \\
\hline Wedge resection & $3(2.2)$ & $9(17.6)$ & $20(64.5)$ & \\
\hline No. of VATS & $86(61.9)$ & $39(76.5)$ & $25(80.6)$ & .042 \\
\hline Operation time (median, IQR) & $100(75-120)$ & $107(80-127)$ & $60(45-90)$ & $<.001$ \\
\hline Chest tube time (median, IQR) & $3(3-5)$ & $3(2-5)$ & $3(2-4)$ & .019 \\
\hline In-hospital stay (median, IQR) & $6(5-7)$ & $6(4-7)$ & $5(3-6)$ & .002 \\
\hline Total drainage (median, IQR) & $570(400-810)$ & $470(230-720)$ & $195(118-410)$ & $<.001$ \\
\hline Complications & $14(10.1)$ & $4(7.8)$ & 0 & .179 \\
\hline Air leak $>7 \mathrm{~d}$ & $11(7.9)$ & $4(7.8)$ & 0 & .269 \\
\hline Chyle leak & $2(1.4)$ & 0 & 0 & .551 \\
\hline Pneumonia & $1(0.7)$ & 0 & 0 & .744 \\
\hline
\end{tabular}

$C M L D$, Complete mediastinal lymph node dissection; $L M L D$, limited mediastinal lymph node dissection; VATS, video-assisted thoracic surgery; IQR, interquartile range. 